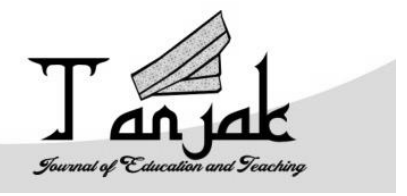

\author{
Tanjak: Journal of Education and Teaching \\ ISSN 2716-4098 (P) 2720-8966 (0) \\ Volume 1 Nomor 2, 2020
}

\title{
PEMBINAAN TERHADAP PERILAKU REMAJA-REMAJA MUSLIM YANG BERADA DI LINGKUNGAN NON MUSLIM OLEH ORANG TUA DI DUSUN KAYU KAWAN DI DESA SEI AKAR KECAMATAN BATANG GANSAL KABUPATEN INDRAGIRI HULU.
}

\author{
Zulhamdan \\ STAIN Sultan Abdurrahman Kepulauan Riau, zulhamdan89@gmail.com
}

DOI: https://doi.org/ 10.35961/tanjak.v1i2.155

\begin{abstract}
Abstrak
Remaja sebagai fase perkembangan sangat rentan akan pengaruh baik atau buruk dari internal maupun eksternal. Oleh karenanya perlu perhatian khusus baik dari orangtua maupun lingkungan sekitar untuk memagari dari pengaruh buruk akibat pergaulan di tengah lingkungan sekitar. Adapun tujuan penelitian ini adalah untuk mengetahui bagaimana perilaku remaja-remaja di Dusun Kayu Kawan Desa Sei Akar Kecamatan Batang Gansal Kabupaten Inragiri Hulu Provinsi Riau dan bagaimana pembinaan yang dilakukan oleh oragtua remaja tersebut. Subjek dari penelitian ini adalah orang tua dan remaja muslim sedangkan objek nya adalah pembinaan orang tua terhadap perilaku remaja muslim. Hasil dari penelitian ini adalah tergolong "Baik". Dan kesimpulan dari penelitian ini adalah Adapun faktor-faktor yang mempengaruhi Pembinaan oleh orang tua terhadap perilaku remaja-remaja muslim adalah: a. Pendidikan orang tua sangat mempengaruhi pembinaan terhadap remaja. b. Pendidikan Remaja bisa mempengaruhi perilaku remaja itu sendiri, c. Keharmonisan Dalam Keluarga menjadi faktor terpenting dalam pembinaan terhadap perilaku remaja oleh orang tua. d. Ekonomi keluarga akan mempermudah orang tua dalam membina perilaku remaja-remaja karna fasilitas remaja bias terpenuhi.
\end{abstract}

Kata Kunci: Pembinaan; Perilaku Remaja; Lingkungan; Orangtua

Tanjak: Jounal of Education and Teaching, Vol. 1, No. 2, 2020 


\begin{abstract}
Adolescents as a developmental phase are very vulnerable to good or bad influences fro, internal and External. Therefore, special attention is needed from both parents and the surrounding environment to protect against bad influences due to association in the surrounding environment. As for the purpose of this study is to find out how the behavior of teenagers in Dusun Kayu Kawan Desa Sei Akar, Batang Gansal District, Indragiri Hulu Regency, Riau Province. The subject of this research is parents and muslim adolescents, while the object is the guidance of parents towards muslim teenager behavior. The result of this study are classified as "Good". And the conclusion of this research is that the factors that influences parental guidance on Muslim teenager's behavior are: a. Parental education greatly affects the development of adolescents, b. adolescents education can influence adolescent behavior itself, c. harmony in the family is the most important factor in fostering adolescent behavior by parents, d. the family economy will make it easier for parents to foster teenager's behavior because youth facilities can be fulfilled.
\end{abstract}

Keywords: Coaching; Adolescent Behavior; Environment; parents

\title{
Pendahuluan
}

Kenakalan remaja diera modern ini sudah melebihi batas yang sewajarnya. Banyak anak dibawah umur sudah mengenal Rokok, Narkoba, Freesex, dan banyak terlibat tindakan kriminal lainnya. Fakta ini sudah tidak dapat dipungkiri lagi, kita dapat melihat brutal nya remaja zaman sekarang. Meningkatnya kriminal di indonesia tidak hanya dilakukan oleh orang dewasa saja, tetapi banyak juga dari kalangan para remaja. Tindakan kenakalan remaja sanagat beraneka ragam dan bervariasi dan lebih terbatas jika dibandingkan tindakan kriminal orang dewasa. Juga motivasi para remaja sering lebih sederhana dan mudah dipahami misalnya : pencurian yang dilakukan oleh seorang remaja, hanya untuk memberikan hadiah kepada mereka yang disukainya dengan maksud untuk mambuat kesan impresif yang baik atau mengagumkan.

Akibatnya para orang tua mengeluhkan perilaku anak-anaknya yang tidak dapat diatur, bahkan terkadang bertindak melawan orang tua mereka. Kalau kita lihat sebelum datangnya islam banyak referensi yang menyebutkan begitu bejat dan tercelanya sifat kaum jahilliyah yang tidak memiliki peradaban, mereka hanya berbuat sesuai nafsu mereka tanpa aturan didalam lingkungan masyarakat yang menjadi norma-norma dalam kehidupan mereka, sehingga mereka berbuat sesuka hati mereka tanpa memikirkan orang lain, dan yang kuat dialah yang menguasai segalanya.

Dengan keadaan seperti ini kemudian Allah SWT mengutus seorang rasul yang terakhir yang diberi tugas untuk menyempurnakan akhlak manusia, sebagaimana yang diterangkan dalam hadits nabi yang artinya sebagai berikut:

Artinya : "Sesunggubnya aku (Muhammad) diutus untuk menyempurnakan akblak manusia". (Ahmad Sunarto, 2005)

Hadits diatas menunjukkan kepada kita bahwa benar-benar nabi kita Muhammad SAW diutus untuk menyempurnakan dan memaksimalkan akhlak yang baik yang seharusnya kita terapkan dalam kehidupan sehari-hari ditengah-tengah kehidupan bermasyarakat, berbangsa dan bernegara. Kehadiran nabi Muhammad SAW memberikan perubahan yang sangat signifikan sehingga dari zaman kegelapan menjadi zaman terang benderang dengan perkembangan ilmu pengetahuan, teknologi yang berkembang begitu pesat.

Tempat perkembangan awal seorang anak sejak dilahirkan sampai proses pertumbuhan dan perkembangannya baik jasmani maupun rohani adalah lingkungan keluarga, oleh karena itu di dalam 
keluargalah dimulainya pembinaan nilai-nilai akhlak karimah ditanamkan bagi semua anggota keluarga termasuk remaja.

Masa remaja merupakan suatu fase perkembangan manusia yang memiliki arti penting bagi kehidupan selanjutnya, karena kualitas kemanusiaannya di masa tua banyak ditentukan oleh caranya menata dan membawa dirinya di masa muda, perubahan yang dialami pada masa ini terjadi secara kodrati dan para ahli menyebutnya sebagai masa transisi.

Masa peralihan yang terjadi pada remaja sangat membingungkan, dalam masa peralihan ini remaja sedang mencari identitasnya. Dalam proses perkembangannya, masa ini senantiasa diwarnai oleh konflik-konflik internal, cita-cita yang melambung, emosi yang tidak stabil serta mudah tersinggung. Oleh karena itu remaja membutuhkan pembinaan agama dari orang tuanya.

Peran dan tanggung jawab orang tua mendidik anak remaja dalam keluarga sangat dominan sebab ditangan orang tuanyalah baik dan buruknya perilaku remaja. Orang tua diberi kewajiban memenuhi hak anak akan pembinaan agama sehingga ia menjadi muslim yang berkualitas. Sebagaimana firman Allah dalam QS At-Tahrim ayat 6 di bawah ini:

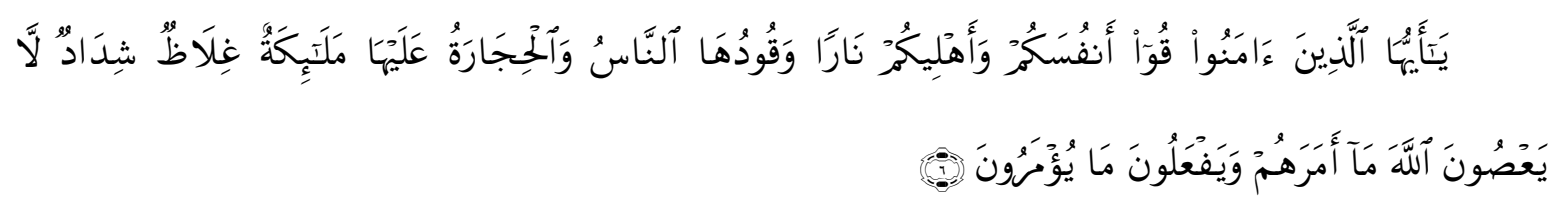

Artinya : Hai orang-orang yang beriman, peliharalah dirimu dan keluargamu dari api neraka yang bahan bakarnya adalah manusia dan batu; penjaganya malaikat-malaikat yang kasar, keras, dan tidak mendurbakai Allah terbadap apa yang diperintabkan-Nya kepada mereka dan selalu mengerjakan apa yang diperintahkan. (Departemen Agama RI Al Qur'an dan Terjemahan: 1989)

Berdasarkan firman Allah SWT diatas, maka dalam membina agama remaja, orang tua dituntut untuk dapat berperan aktif karena masa remaja merupakan masa transisi yang kritis, masa remaja adalah masa transisi dari anak-anak menuju dewasa sehingga individu pada masa ini mengalami berbagai perubahan baik fisik, perilaku dan sikap sehingga perubahan ini patut diwaspadai. (Hurlock: 1992).

\section{Metode Penelitian}

Jenis penelitian ini adalah Kuantitatif Deskritif. Tempat Penelitian ini dilakukan oleh peneliti berlokasi di Dusun Kayu Kawan Desa Sei Akar Kecamatan Batang Gansal Kabupaten Indragiri Hulu. Penelitian ini didasari dengan alasan bahwa persoalan-persoalan yang dikaji penulis berada dilokasi tersebut. Penelitian ini dilaksanakan kurang lebih 3 (tiga) bulan yakni dari tanggal 1 Juni - 30 Agustus 2013

Adapun subjek pada penelitian ini adalah Orang tua dan remaja-remaja muslim di Dusun Kayu Kawan Desa Sei Akar Kecamatan Batang Gansal Kabupaten Indragiri Hulu. Sedangkan objek penelitian ini adalah pembinaan perilaku remaja-remaja muslim di Dusun Kayu Kawan Desa Sei Akar Kecamatan Batang Gansal Kabupaten Indragiri Hulu.

Populasi adalah wilayah generalisasi yang terdiri atas objek/subjek yang mempunyai kualitas dan karakteristik tertentu yang ditetapkan oleh peneliti. (Sugiyono: 2009) 
Populasi pada penelitian ini adalah seluruh orang tua dan remaja muslim yang berjumlah 60 orang, yang terdiri dari 40 orang tua dan 20 remaja muslim.

Mengingat jumlah populasinya tidak terlalu banyak, maka penulis mengambil sampel secara keseluruhan dari jumlah populasi dalam penelitian ini yang berjumlah 60. Maka penelitian ini menggunakan tekhnik sampling secara keseluruhan

Dalam penelitian ini penulis memakai teknik pengumpulan data sebagai berikut :

a. Wawancara atau interview, digunakan sebagai teknik pengumpulan data untuk mendapatkan keterangan-keterangan secara lisan yang diajukan kepada orang tua dan remaja di Dusun Kayu Kawan Desa Sei Akar guna mendapatkan data tentang subjek.

b. Quesioner (Angket) adalah teknik pengumpulan data yang dilakukan dengan cara memberi seperangkat pertanyaan atau pernyataan tertulis kepada responden untuk di jawab. (Sugiyono: 2009, 23)

Dalam penelitian ini yang berjudul penbinaan terhadap perilaku remaja-remaja muslium yang berada dilingkungan kristen oleh orang tua didusun kayu kawan desa sei akar penulis menggunakan teknik analisa persentase dengan rumus : $\mathrm{P}=(\mathrm{F}: \mathrm{N}) \mathrm{X} 100 \%$

Keterangan :

$\mathrm{P}=$ Proporsi

$\mathrm{F}=$ Frekwensi

$\mathrm{N}=$ Jumlah subjek secara keseluruhan

Setelah data terkumpul maka, untuk ukuran sangat baik, baik, cukup baik, kurang baik, tidak baik sebagai berikut :

a. $80 \%-100 \%$ ( Sangat Baik)

b. $60 \%-79,99 \%$ (Baik)

c. $40 \%-59,99 \%$ (Cukup Baik)

d. $20 \%-39,99 \%$ ( Kurang Baik )

e. $0 \%-19,99 \%$ ( Tidak Baik ). (Riduwan Dos dan Akdon: 2005)

Untuk menganalisa data dalam penelitian ini, penulis menggunakan teknik deskriptif kualitatif dengan persentase, yaitu apabila data telah dikumpulkan, maka di klasifikasikan menjadi dua, yaitu data kualitatif yang digambarkan dengan kata-kata, atau kalimat yang dipisahkan menurut kategori untuk memperoleh kesimpulan. Dan data kualitatif yang terwujud angka-angka hasil perhitungan atau pengukuran dapat diproses dengan cara dijumlahkan dan diperoleh hasil prosentase, kemudian ditafsirkan dengan kalimat yang bersifat kualitatif, yakni :

\section{$P=(F: N) X 100 \%$.}

Setelah data terkumpul, maka untuk ukuran sangat baik, baik, cukup baik, kurang baik, tidak baik. Sebagai berikut :
a. $\quad 80 \%-100 \%$
: Pembinaan terhadap perilaku remaja-remaja muslim yang berada dilingkungan kristen oleh orang tua di Dusun Kayu Kawan Desa Sei Akar Kecamatan Batang Gansal dikategorikan sangat baik.
b. $\quad 60 \%-79 \%$
: Pembinaan terhadap perilaku remaja-remaja muslim yang berada dilingkungan kristen oleh orang tua di Dusun Kayu Kawan Desa Sei Akar Kecamatan 

c. $\quad 40 \%-59 \%$
: Pembinaan terhadap perilaku remaja-remaja muslim yang berada dilingkungan kristen oleh orang tua di Dusun Kayu Kawan Desa Sei Akar Kecamatan Batang Gansal dikategorikan cukup baik.
d. $\quad 20 \%-39 \%$
: Pembinaan terhadap perilaku remaja-remaja muslim yang berada dilingkungan kristen oleh orang tua di Dusun Kayu Kawan Desa Sei Akar Kecamatan Batang Gansal dikategorikan kurang baik.
e. $\quad 0 \%-19 \%$
Pembinaan terhadap perilaku remaja-remaja muslim yang berada dilingkungan kristen oleh orang tua di Dusun Kayu Kawan Desa Sei Akar Kecamatan Batang Gansal dikategorikan tidak baik.

Batang Gansal dikategorikan baik.

Adapun tujuan penelitian ini adalah untuk mengetahui bagaimana perilaku remaja-remaja di Dusun Kayu Kawan Desa Sei Akar Kecamatan Batang Gansal Kabupaten Inragiri Hulu Provinsi Riau dan bagaimana pembinaan yang dilakukan oleh oragtua remaja tersebut.

\section{Hasil dan Pembahasan}

Untuk mengetahui hasil dari peneitian ini yang berjudul tentang Pembinaan terhadap perilaku remaja-remaja muslim yang berada dilingkungan kristen oleh orang tua di Dusun Kayu Kawan Desa Sei Akar Kecamatan Batang Gansal dikategorikan sangat baik, baik, cukup baik, kurang baik, dan tidak baik dapat dilihat pada rekapitulasi sebagai berikut :

Tabel.1

Rekapitulasi Tentang Pembinaan Terhadap Perilaku Remaja-Remaja Muslim yang Berada Dilingkungan Kristen Oleh Orang Tua di Dusun Kayu Kawan Desa Sei Akar Kecamatan Batang Gansal.

\begin{tabular}{|c|c|c|c|c|c|c|c|c|c|}
\hline \multirow{2}{*}{ No. } & \multicolumn{2}{|c|}{$\mathrm{A}$} & \multicolumn{2}{|c|}{$\mathrm{B}$} & \multicolumn{2}{|c|}{$\mathrm{C}$} & \multicolumn{2}{|c|}{$\mathrm{D}$} & \multirow{2}{*}{ Jumlah } \\
\cline { 2 - 8 } & $\mathrm{F}$ & $\%$ & $\mathrm{~F}$ & $\%$ & $\mathrm{~F}$ & $\%$ & $\mathrm{~F}$ & $\%$ & \\
\hline 1 & 12 & 20,00 & 9 & 15,00 & 30 & 50,00 & 9 & 15,00 & 60 \\
2 & 20 & 33,33 & 11 & 18,33 & 17 & 28,34 & 12 & 20,00 & 60 \\
3 & 19 & 31,67 & 20 & 33,33 & 16 & 26,67 & 5 & 8,33 & 60 \\
4 & 18 & 30,00 & 16 & 26,67 & 22 & 36,66 & 4 & 6,67 & 60 \\
5 & 24 & 40,00 & 21 & 35,00 & 13 & 21,67 & 2 & 3,33 & 60 \\
6 & 17 & 28,33 & 26 & 43,33 & 16 & 26,67 & 1 & 1,67 & 60 \\
7 & 20 & 33,33 & 23 & 38,33 & 13 & 21,67 & 4 & 6,67 & 60 \\
8 & 10 & 16,67 & 23 & 38,33 & 18 & 30,00 & 9 & 15,00 & 60 \\
9 & 15 & 25,00 & 19 & 31,67 & 23 & 38,33 & 3 & 5,00 & 60 \\
10 & 22 & 36,66 & 17 & 28,34 & 16 & 26,67 & 5 & 8,33 & 60 \\
11 & 11 & 18,33 & 21 & 35,00 & 18 & 30,00 & 10 & 16,67 & 60 \\
12 & 14 & 23,33 & 19 & 31,67 & 18 & 30,00 & 9 & 15,00 & 60 \\
13 & 11 & 18,33 & 14 & 23,33 & 22 & 36,67 & 13 & 21,67 & 60 \\
14 & 8 & 13,33 & 12 & 20,00 & 19 & 31,67 & 21 & 35,00 & 60 \\
15 & 32 & 53,33 & 12 & 20,00 & 15 & 25,00 & 1 & 1,67 & 60 \\
16 & 20 & 33,33 & 17 & 28,33 & 13 & 21,67 & 10 & 16,67 & 60 \\
17 & 12 & 20,00 & 15 & 25,00 & 21 & 35,00 & 12 & 20,00 & 60 \\
18 & 20 & 33,33 & 12 & 20,00 & 17 & 28,33 & 11 & 18,34 & 60 \\
19 & 30 & 50,00 & 21 & 35,00 & 8 & 13,33 & 1 & 1,67 & 60 \\
20 & 29 & 48,33 & 20 & 33,33 & 10 & 16,67 & 1 & 1,67 & 60 \\
\hline
\end{tabular}

Tanjak: Jounal of Education and Teaching, Vol. 1, No. 2, 2020 


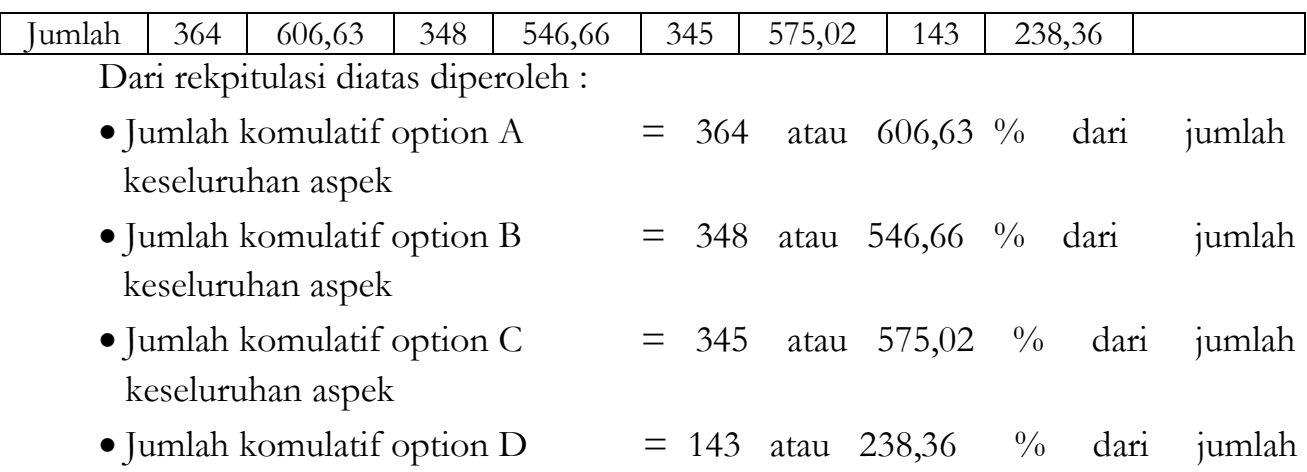

keseluruhan aspek

Jadi jumlah keseluruhannya adalah $364+348+345+143=1.200$

Selanjutnya untuk penilaian pada masing-masing option diberi bobot sebagai berikut :

Option A diberi bobot 4

Option B diberi bobot 3

Option C diberi bobot 2

Option D diberi bobot 1

Dengan demikian skor tertinggi tentang pembinaan terhadap perilaku remaja-remaja muslim yang berada dilingkungan kristen oleh orang tua di Dusun Kayu Kawan Desa Sei Akar Kecamatan Batang Gansal adalah 1.200 X $4=4.800$ dan skor terendah adalah 1.200 X $1=1.200$. Selanjutnya untuk mengetahui hasil baik tidaknya tentang pembinaan terhadap perilaku remaja-remaja muslim yang berada dilingkungan kristen oleh orang tua di Dusun Kayu Kawan Desa Sei Akar Kecamatan Batang Gansal adalah dengan langkah sebaagai berikut :
a. $364 \times 4=1.456$
b. $348 \times 3=1.044$
c. $345 \times 2=690$
d. $143 \times 1=\underline{143}$

$$
3.333
$$

Lalu hasil yang diperoleh dibandingkan dengan hasil yang diharapkan untuk memperoleh persentase sebagai berikut :

$$
\mathrm{P}=\frac{3.333}{4.800} \times 100 \%=69,44 \%
$$

Berdasarkan persentase di atas maka dapat disimpulkan bahwa tentang pembinaan terhadap perilaku remaja-remaja muslim yang berada dilingkungan kristen oleh orang tua di Dusun Kayu Kawan Desa Sei Akar Kecamatan Batang Gansal adalah "Baik" karena mencapai 69,44 \% dari ketentuan yang telah ditetapkan, karena berada pada rentang nilai 60\% - 80\% yang tergolong "Baik".

Tabel.2

Faktor-Faktor Yang Mempengaruhi Pembinaan Orang Tua Terhadap Remaja

\begin{tabular}{|c|l|c|c|}
\hline Option & Alternatif Jawaban & F & $\%$ \\
\hline A. & Pendidikan Orang Tua & 9 & 15 \\
B. & Pendidikan Remaja & 12 & 20 \\
C. & Keharmonisan Dalam Keluarga & 29 & 48 \\
D. & Ekonomi Keluarga & 10 & 17 \\
& & & \\
\hline
\end{tabular}




\begin{tabular}{|c|c|c|c|}
\hline Jumlah & & 60 & 100 \\
\hline
\end{tabular}

Dari tabel diatas terlihat faktor yang paling dominan yang mempengaruhi pembinaan oleh orang tua terhadap remaja adalah keharmonisan dalam keluarga hal ini tergambar dengan responden menjawab 29 (48 \%). Dan wawancara dengan tokoh pemuda yakni Ali Arkam mengatakan keharmonisan sangat penting di jaga agar tidak ada jarak antara orang tua dan anak.

a. Pendidikan orang tua

Pendidikan orang tua merupakan salah satu faktor yang mempengaruhi, sebagai orang tua yang berpendidikan akan lebih dapat mengarahkan anak remaja dalam bergaul dan dalam menentukan dan dalam menentukan sekolah apa yang mampu membentuk perilaku anak.

b. Pendidikan Remaja

Tingkat pendidikan remaja menjadi salah satu faktor yang mempengaruhi perilaku remaja itu sendiri, semakin tinggi pendidikan remaja maka semakin banyak ilmu yang diperoleh dan seharusnya semakin baik pula perilakunya.

c. Keharmonisan Dalam Keluarga

Sebagai orang tua sudah seharusnya menjaga keharmonisan dalam keluarga, dengan menjaga komunikasi yang baik terhadap anak-anaknya dirumah sehingga pembinaan yang dilakukan oleh orang tua bias berjalan seperti yang diharapkan dan memudahkan orang tua dalam mengontrol perilaku anakanaknya. Sehingga anak-anak pun merasa dihargai sehingga mereka lebih mudah untuk dibina.

\section{d. Ekonomi keluarga}

Ekonomi yang baik akan membuat orang tua akan menjadi mudah dalam membina perilaku remaja, karena Kebutuhan para remaja sangat komplek yang mana remaja selalu mencari kebutuhan yang tidak dipenuhi oleh kedua orang tuanyadiluar rumah,bila kebutuhan sarana dan prasarana yang dibutuhkan oleh remaja ada tersedia oleh orang tua, remaja akan betah tinggal dirumah hal ini juga akan meminimalisir pergaulan remaja dengan hal-hal yang negatif karena remaja selalu terkontrol oleh kedua orang tuanya.

A. Dasar dan Tujuan Pembinaan Oleh Orang Tua Terhadap Prilaku Remaja

1. Dasar Pembinaan Agama Islam

Pembinaan agama islam merupakan bagian dari dakwah islamiyah untuk beramal ma'ruf nahi munkar dalam kehidupan sehari-hari di masyarakat. Dalam Al-qur'an Allah SWT berfirman dalam surat At-Taubah Ayat 71

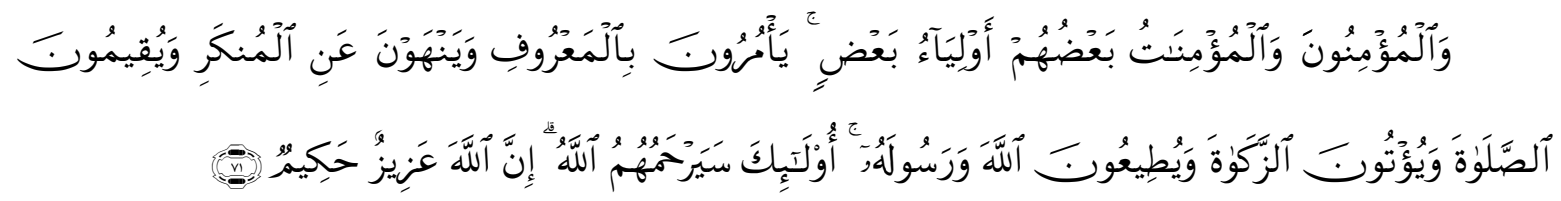

Artinya :Dan orang-orang yang beriman, lelaki dan perempuan, sebabagian mereka (adalab) menjadi penolong bagi sebahagian yang lain. mereka menyuruh (mengerjakan) yang ma'ruf, mencegah dari yang munkar, mendirikan shalat, menunaikan zakat dan mereka taat pada Allah dan Rasul-Nya. mereka itu akan diberi rahmat oleh Allab; Sesungguhnya Allah Maha Perkasa lagi Maha Bijaksana. 
Dari ayat diatas, dapat diambil pengertian bahwa setiap muslim berkewajiban untuk mengajak sesamanya agar mengerjakan yang ma'ruf dan mencegah kemunkaran, termasuk orang tua yang berkewajiban membina anak-anaknya agar mereka menjadi anak yang sholeh serta menjalankan ajaran agama islam sesuai dengan ketentuan Allah SW'T dan Rasulnya.

2. Tujuan Pembinaan Agama Islam

Setiap perbuatan yang dilakukan manusia pasti mempunyai tujuan, demikian pula dalam pembinaan agama islam sebagaimana yang dikemukakan oleh Zakiah Darajad bahwa pembinaan mental agama islam mempunyai tujuan untuk membina moral atau mental kearah yang sesuai dengan ajaran agama, artinya setelah pembinaan itu terjadi, remaja dengan sendirinya akan menjadikan agama sebagai pedoman dan pengendalian tingkahlaku, sikap dan gerak gerik dalam hidup. (Zaqiyah Derajat: 1975, 4)

Sedangkan menurut M.Arifin bahwa tujuan pembinaan agama sebagai berikut :

a. Penjiwaan agama terhadap remaja sebagai usaha mengatasi problem-problem yang menyangkut pengajaran, studi atau menyangkut kehidupan pribadi akibat ganguan jiwa dan sebagainya.

b. Mengintensifkan penjiwaan agama tersebut sampai kepada mengamalkan ajaran agama remaja tersebut. (M.Arifin: 1979)

Dari uraian diatas, maka penulis memberikan kesimpulan bahwa pembinaan mempunyai tujuan untuk membina umat islam dalam rangka memelihara dan meningkatkan pengamalan ajaran agama islam dalam kehidupan sehari-hari termasuk peningkatan iman kepada Allah SWT, di sertai dengan perbuatan baik yang mengandung unsur ibadah.

B. Metode Pembinaan Oleh Orang Tua Terhadap Prilaku Remaja

Adapun metode yang digunakan untuk membiasakan anak remaja dalam berprilaku baik sebagai berikut :

1. Teladan

Anak remaja mempunyai dorongan untuk meniru terhadap apa yang didengar dan dilihatnya. Dengan teladan ini timbullah gejala identifikasi positif yaitu penyamaan diri dengan orang yang ditiru. (Ahmad Marimba: 1989, 105). Identifikasi positif sangat penting dalam pembentukan kepribadian remaja, untuk itu orang tua harus bisa menjadi tokoh dalam identifikasi bagi anakanaknya, artinya segala tingkah laku dan perbuatan orang tua menjadi contoh bagi anak-anaknya.

2. Anjuran

Anjuran adalah membina dengan cara menyuruh untuk melakukannya disini remaja mendengarkan apa yang harus dilakukannya, dalam anjuran ini sekaligus memberi pengertian dan nasehat untuk membentuk sifat dan pribadi yang disiplin.

3. Latihan

Latihan yang dimaksud adalah upaya untuk membiasakan remaja agar mereka menguasai gerakan dan menghafal apa yang telah remaja tersebut pelajari. Dalam melakukan ibadah tersebut maka gerakan dan ucapan ini penting artinya. (Ahmad Marimba: 1989, 105)

4. Koreksi Dan Pengawasan

Koreksi dan Pengawasan ini dilakukan mengingat manusia bersifat tidak sempurna, kemungkinan untuk berbuat kesalahan, penyimpangan dari anjuran selalu ada, apalagi masa remaja sangat labil. Koreksi dan pengawasan ini untuk menghindari remaja berbuat hal yang melanggar aturan agama dan agar lebih berhati-hati jika mengerjakan sesuatu.

5. Larangan 
Untuk mencegah anak berbuat sesuatu yang nyata-nyata salah sebagaimana perintah atau larangan harus disesuaikan dengan kondisi remaja, sehingga remaja dengan mudah mematuhi larangan yang diketahui. Orang tua harus berusaha menerangkan mengapa sesuatu itu dilarang, dengan demikian remaja tidak berfikir macam-macam dan akhirnya remaja akan merasa puas atas jawaban. (Ahmad Marimba: 1989, 109)

6. Hadiah

Untuk mendorong remaja berbuat kebajikan, hendaknya orang tua selalu memberi penghargaan atau hadiah. Hadiah tidak hanya berupa barang tetapi bisa berupa sanjungan, anggukan, acungan jempol dan wajah yang berseri supaya remaja merasa diperhatikan dan dihargai jerih payahnya, sehingga akan selalu membuat anak semangat untuk melakukan sesuatu hal.

7. Hukuman

Hukuman diberikan jika melakukan pelanggaran terhadap perintah atau lupa melakukan sesuatu yang menjadi kewajibannya. Hal ini dilakukan jika cara-cara yang lain sudah tidak bisa digunakan lagi. Hukuman tidak perlu hukuman badan. (M.Arifin: 1979, 53-54.)

C. Perilaku Remaja

Pengertian perilaku secara khusus yang diutarakan oleh Mahfud Shalahudin adalah perilaku mempunyai arti konkret dari jiwa karena lebih konkret itu, maka perilaku lebih mudah dipelajari dari pada jiwa dan melalui tingkah laku pula kita akan dapat mengenal seseorang. Termasuk dalam tingkah laku disini adalah perbuatan-perbuatan yang terbuka (yaitu perbuatan yang dapat dilihat oang lain seperti makan, minum, bebicara,dll) dan tingkah laku tertutup (yaitu jenis perbuatan yang diketahui secaratidak langsung seperti melalui alat atau metode khusus seperti berfikir, sedih, berkhayal, dll).

Dipandang dari aspek biologis perilaku adalah suatu kegiatan atau aktivitas organisme atau makhluk hidup yang bisa dilihat sedangkan perilaku manusia pada hakikatnya adalah tindakan atau aktivitas dari manusia itu sendiri yang mempunyai bentangan yang sangat luas antara lain berjalan, berbicara, menangis, tertawa, membaca dan sebagainya, sehingga dapat disimpulkan bahwa perilaku manusia adalah semua kegiatan atau aktivitas manusia baik yang dapat diamati langsung maupun yang tidak dapat diamati oleh pihak luar.

Sedangkan tingkah laku adalah Aktivitas yang ada pada individu atau organisme yang tidak timbul dengan sendirinya, tetapi sebagai akibat dari adanya stimulus atau rangsangan yang mengenai organism tersebut, tingkah laku atau aktivitas total merupakan jawaban atau respon terhadap stimulus yang mengenainya. Sedangkan tingkah laku dilihat dari kacamata agama atau pandanga islam akan nampak relevansinya dengan seruan untuk bertaqwa kepada Allah SWT, hal tersebut relevan dengan fitrah manusia sebagai makhluk paling sempurna di banding dengan makhluk lainnya; seperti yang tercantum dalam Q.S Ar-Rum : 30

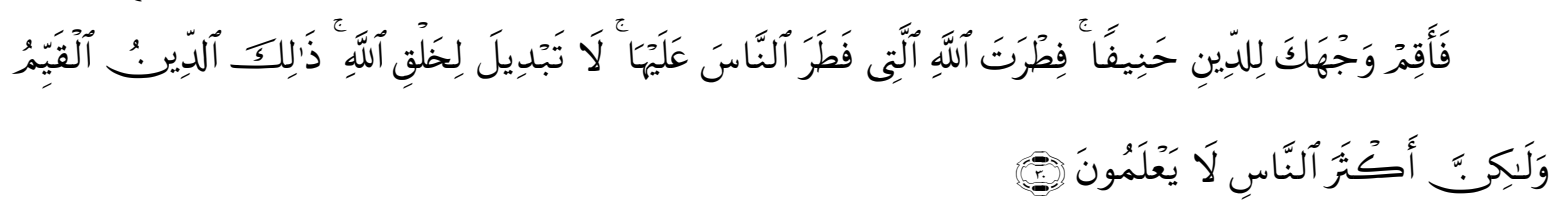

Artinya : Maka hadapkanlah wajahmu dengan Lurus kepada agama Allab; (tetaplah atas) fitrah Allah yang telah menciptakan manusia menurut fitrah itu. tidak ada peubahan pada fitrah Allah. (Itulah) agama yang lurus; tetapi kebanyakan manusia tidak mengetabui. 
Remaja berasal dari kata latin Adolensence yang berarti tumbuh atau tumbuh menjadi dewasa. Istilah adolensence mempunyai arti yang lebih luas lagi yang mencakup kematangan mental, emosional sosial dan fisik. Pada masa ini sebenarnya tidak mempunyai tempat yang jelas karena tidak termasuk golongan anak tetapi tidak juga golongan dewasa atau tua.

Masa remaja berlangsung antara umur 12 tahun sampai dengan 21 tahun bagi wanita dan 13 tahun sampai dengan 22 tahun bagi pria. Sedangkan pengertian remaja menurut Zakiah Darajat adalah Masa peralihan diantara masa kanak-kanak dan dewasa. Dalam masa ini anak mengalami masa pertumbuhan dan masa perkembangan fisiknya maupun perkembangan psikisnya. Mereka bukanlah anak-anak baik bentuk badan ataupun cara berfikir atau bertindak, tetapi bukan pula orang dewasa yang telah matang.

Definisi remaja yang dipaparkan oleh Zakiah Darajat tersebut menggambarkan bahwa masa remaja adalah masa peralihan dari masa anak-anak dengan masa dewasa dengan rentang usia antara 1222 tahun, dimana pada masa tersebut terjadi proses pematangan baik itu pematangan fisik, maupun psikologis.

Dari uraian diatas, maka penulis memberikan kesimpulan bahwa perilaku remaja merupakan sikap maupun perbuatan yang dilakukan remaja secara tidak langsung baik melalui alat atau metode khusus seperti berfikir, sedih, berkhayal, dll.

\section{Kesimpulan}

Dari hasil pembahasan penelitian diatas, maka pada bagian ini akan ditarik beberapa kesimpulan sebagai berikut :

Pembinaan terhadap perilaku remaja-remaja muslim yang berada dilingkungan kristen oleh orang tua di Dusun Kayu Kawan Desa Sei Akar Kecamatan Batang Gansal adalah " Baik " karena mencapai persentase $69,44 \%$ dari ketentuan yang telah ditetapkan, karena berada pada rentang nilai $60 \%-80 \%$ yang tergolong "Baik “.

Adapun faktor-faktor yang mempengaruhi Pembinaan oleh orang tua terhadap perilaku remajaremaja muslim yang berada dilingkungan kristen di Dusun Kayu Kawan Desa Sei Akar Kecamatan Batang Gansal adalah: a. Pendidikan orang tua sangat mempengaruhi pembinaan terhadap remaja. b. Pendidikan Remaja bisa mempengaruhi perilaku remaja itu sendiri c. Keharmonisan Dalam Keluarga menjadi faktor terpenting dalam pembinaan terhadap perilaku remaja oleh orang tua. d. Ekonomi keluarga akan mempermudah orang tua dalam membina perilaku remaja-remaja karna fasilitas remaja bias terpenuhi

\section{Ucapan Terimakasih}

Terimakasih sebesar-besarnya kepada seluruh pihak yang telah berjasa berupa sumbangan pemikiran, motivasi maupun hal lainnya sehingga penulis mampu menyelesaikan penerbitan jurnal ini. 


\section{Referensi}

Agama RI, Departemen (1989). Al Qur'an dan Terjemahan, Jakarta: (Proyek Pengadaan Kitab Suci)

Ali , M. Nashir (1985) Dasar-Dasar Ilmu Mendidik, Jakarta: Mutiara Sumber Widya,

Arifin, M. (1979) Pokok-Pokok Tentang Bimbingan Dan Penyuluban Agama, Jakarta: Bulan Bintang

Darajat, Zaqiyah (1970) Ilmu Jiwa Agama, Jakarta: Bulan Buntang,

Derajat, Zaqiyah (1975) Kesehatan Mental, Jakarta: Gunung Agung,

Hurlock (1992) Terjemahan, Peranan Remaja Dalam Kemerdekaan, Jakarta: PT. Ahyar Soecipto

Marimba, Ahmad (1989). Pengantar Filsafat Pendidikan Islam Bandung: PT. Al-ma'ruf.

Pendidikan dan Kebudayaan, Departemen (1991) Kamus Besar Bahasa Indonesia Jakarta: Balai Pustaka,

Poerwadarminta (1976) Kamus Bahasa Indonesia, Jakarta: Balai Pustaka

Rahmat, Jalaluddin dan Gandaatmaja Mukhtar (1993) Keluarga Muslim Dalam Masyarakat Modern, Bandung: PT. Remaja Rosdakarya

Riduwan, dan Dos Akdon (2005) Rumus dan Data Dalam Aplikasi Statistika, Bandung: Alfa Beta.

Rubiyanto, (1999) Tugas Orang Tua, Bandung: Bumi Aksara

Sugiyono, (2009) Metode Penelitian Pendidikan, Bandung: Alfa Beta

Sunarto, Ahmad (2005.) Hadits Jami'us Shagir. Jakarta: An-Nur.

Syakir, Asmuni (1993). Dasar-dasar Strategi Dakwah Islam. Bandung: Alfabeta.

illness (pp. 517-552). Washington, DC: American Psychiatric Press.

Freudenthal, H. (2012). Revisiting mathematics education. New York: Kluwer Academic Publisher.

Herculano-Houzel, S., Collins, C. E., Wong, P., Kaas, J. H. \& Lent, R. (2008). The basic nonuniformity of the cerebral cortex. Proceedings of the National Academy of Sciences, 105, 12593-12598. doi:10.1073/pnas.0805417105

Iacono, W. G. (2008). Polygraph testing. In E. Borgida \& S. T. Fiske (Eds.), Beyond common sense: Psychological science in the courtroom (pp. 219-235). doi: 10.1002/9780470696422(

Osman, M. (2010). Controlling uncertainty: A review of human behavior in complex dynamic environments. Psychological Bulletin, 136(1), 65-86. doi: 10.1037/a0017815

Rahman, M. (2013). Using authentic materials in the writing classes: Tertiary level scenario. (Unpublished master's thesis). BRAC University, Mohakhali, Dhaka, Bangladesh. Scheinin, P. (2009). Using student 
assessment to improve teaching and educational policy. In M. O'Keefe, E. Webb, \& K. Hoad (Eds.), Assessment and student learning: Collecting, interpreting and using data to inform teaching (pp. 12-14). Melbourne, Australia: Australian Council for Educational Research.

Scott, D. (2015). Colonial governmentality. In J. X. Inda (Ed.), Anthropologies of modernity (pp. 21-49). Retrieved from http://www3.interscience.wiley.com/cgi-bin/bookhome/117909832 